\title{
Accommodating culture and cultural diversity in online teaching
}

\author{
Annegret Goold, Annemieke Craig and Jo Coldwell \\ Deakin University
}

\begin{abstract}
The term 'culture' has been in common use for a long time. However there is no universally accepted definition and hence it is important to define clearly what culture means in a particular research context. The research reported here is part of a project undertaken at a large Australian university in late 2005. The overall aim of the project was to identify the characteristics of culture and cultural diversity, and to consider how these manifested themselves when teaching and learning in an online environment. This paper reports on particular outcomes from the second stage of the project. This involved conducting focus groups with experienced academics and educational developers of online units. The aim was to gain an understanding of culture and cultural difference in the online environment and to consider what strategies were effective in teaching a culturally diverse cohort of online students. The findings from the focus group sessions were benchmarked with other external faculty. The cultural factors of ethnicity and language, attitudes to educational learning, education and prior learning, learning styles and socio-economic background were well supported by the external faculty. However the factors of religion and gender were not supported. Practices for accommodating such cultural differences amongst students within the online class are presented.
\end{abstract}

\section{Introduction}

The first known definition of culture dates back to the 18th century when Sir Edward Burnett Tylor defined culture as 'that complex whole which includes knowledge, belief, art, morals, law, custom, and any other capabilities and habits acquired by man as a member of society' (Tylor, 1871). However the term 'culture' has more than one definition and Williams (1983; p.87) goes so far as to suggest that culture 'is one of the two or three most complicated words in the English language'. The Oxford Online Reference Premium (2007) produces some 492 definitions of the term culture and these definitions include 'production of organisms', 'intellectual development and tastes', 'form or type of civilization' and the 'customs of a people'. Consequently Choi (1995) suggests that since there are various 
definitions of culture and there is no clear consensus on its meaning, it is critical to define the use of the term in any given research area.

The research reported here is the second stage of a three-part research project which was undertaken through a Strategic Teaching and Learning Grant at Deakin University in 2005. The overall aim of the project was to identify the characteristics of culture and cultural diversity (as perceived by staff and students at Deakin) and to discover how these characteristics manifest themselves when teaching and learning in an online environment. The first stage of the study involved a review of the literature. The second stage of the study was a series of focus groups of staff experienced with online course design, development, implementation and operation (teaching). The findings from these focus groups were then benchmarked with attendees at a workshop at the Asia-Pacific WebCT User Conference in September 2005, involving 20 external faculty. An online, University wide student survey was the final part of the study.

This paper reports on the particular outcomes from the focus groups. The participants of the University focus groups were asked to comment about their understanding of culture and cultural difference in the educational setting, and how they might go about teaching effectively for cultural difference and diversity online. They were also asked to comment on different cultural influences that affect the way their students go about learning, and how learning might be facilitated in a culturally diverse online environment.

\section{Background}

In the last two decades higher education in Australia has been transformed. In 1988 a dual system, consisting of nineteen universities and fifty-seven colleges of advanced education, was replaced with the Unified National System (Meek \& Harman, 1993). While the missions of the original two types of institutions had been quite different (for example vocationally oriented colleges were not funded for research), mergers and amalgamations resulted in less than forty institutions - all called universities (Maslen \& Slattery, 1994). Most of these universities were large multi-campus institutions.

At the same time retention rates in high schools more than doubled. The increase in retention rates was due to changing community expectations, a depressed teenage labour market and government policies that encouraged students to complete their secondary education (Williams, Long, Carpenter \& Hayden, 1993). More students than ever before became eligible to enter university. As enrolments skyrocketed from 348,500 in 1983 to 570,000 in 1993, universities were forced to become more self sufficient. This increase 
in student numbers was not accompanied by an equivalent increase in federal funding.

From the early 1950s international students from Asia and the Pacific came to Australia to study under the Colombo Plan (Maslen \& Slattery, 1994). Various aid programs enabled students to be partly or fully subsidised. In 1986 legislative changes enabled universities to charge full fees for international students 'making a commodity of what was once a form of foreign aid' (Maslen \& Slattery, 1994; p.185). From 1987 Australian students were also required to make a contribution towards the cost of their education by paying a small annual administration fee of $\$ 250$. This was replaced in 1989 with the introduction of the Higher Education Contribution Scheme, with Australian students being charged a more substantial fee, though still significantly less than the international student fees charged by universities (Maslen \& Slattery, 1994). At this time universities also began taking their courses overseas. Education services were delivered through joint ventures, affiliated colleges, twinning arrangements with partner universities and distance education, all of which enabled students from other countries to take part in the Australian education sector.

Since the 1930s educators have used the concept of the learning environment to refer to the traditional classroom environment (Chang \& Fisher, 2003). Teaching in the traditional classroom consists of the delivery of lectures as well as tutorials, workshops or laboratories. Lectures facilitate the mainly one way transmission of information from staff to large groups of students, while the smaller tutorial, workshop or laboratory classes enable face to face interaction and discussion between all involved. Distance education consists of the provision of resources and materials by post, with students predominately working independently. The $1990 \mathrm{~s}$ enabled distance education students to also communicate with teaching staff via email and bulletin boards.

Advances in technology in the last decade have opened up new ways for the delivery of learning materials and teacher-student interactions. Online learning environments (OLEs) have allowed the development of the online or virtual classroom. Students studying at twinning partner institutions and those studying in distance education mode can now be amalgamated with students studying in traditional modes into this virtual classroom. Classes are no longer constrained by physical walls. Students interact with online technologies and, as Campbell, Goold and Goward (2004) found, there appears to be little difference in the use of online technologies and resources among local and non-local students.

These changes have resulted in a very different cohort of students in new types of classes. Traditional on campus students have face to face classes 
supplemented, and in some cases replaced, by online learning environments. Online environments provide off campus students with the opportunity for better interaction with their fellow students and their teachers. Students in geographically dispersed locations and from widely dispersed backgrounds can now more easily participate in group work. With these new online learning environments there is a greater need for effective communication and collaboration. However the reality is that with the greater diversity of students within the student cohorts, communication and collaboration are not straightforward. While there is potential for cross-cultural learning through interactions with students from diverse backgrounds and cultures, there is also the potential for misunderstanding and confusion.

Singh, O'Donoghue and Worton (2005; p.22) warn that this 'diversity of the new student population requires that institutions carefully develop programmes that will satisfy a broad range of learning requirements'. It is necessary then to consider whether the online learning environments are meeting the needs of this broad population of students or if they are disenfranchising culturally diverse students. Jones (2005) further suggests that it is necessary to also understand how pedagogy, curricular philosophies and the teacher's awareness of the cultural differences amongst their class can influence the learner.

While an increasing number of international students may appear to increase the cultural diversity within a university, unless that diversity is valued and incorporated in practical terms into curricula, then the diversity of students does not actually add to internationalisation of the curricula (Das, 2005). Instead it adds to a series of problems for international students struggling to fit into the dominant literacy which does not recognise their own culturally based ways of knowing, learning and expressing their knowledge (Liddicoat, 2004; Mackinnon \& Manathunga, 2003). Jolley (1997, p.26) suggests however that appropriate use of online learning environments can add value to the design of internationalised learning experiences by 'promoting cultural awareness as learners engage in the electronic exchange of ideas, experiences and educational material'.

The changing face of the university class is not restricted to Australia. A three-fold increase in students at one institution in New Zealand, for example, meant that $63 \%$ of the students enrolled in the Business Faculty were international students in 2003. This prompted Sherry, Bhat, Beaver and Ling $(2004 ;$ p.1) to argue that with such a 'dramatic increase in the number of international students, the challenge for students and teachers is to be able to measure the legitimate needs and expectations of services offered to this group of students'. 


\section{The research questions}

The questions to be answered by this research were:

- What did academics, who were experienced in the development and delivery of online units, regard as culture and cultural diversity?

- How did culture and cultural diversity manifest itself when teaching online?

- What was being done to accommodate cultural diversity in an online learning environment?

- What could be considered as best practice in teaching for a culturally diverse student cohort?

\section{Method}

This research was conducted at Deakin University, a large Australian university, which has embraced online technologies to support its goals of being progressive, relevant, innovative and responsive.

The study was undertaken in Semester 2, 2005. At that time there were 23 units delivered wholly online at Deakin, involving each of the five Faculties of Arts, Business and Law, Education, Health and Behavioural Sciences, and Science and Technology. These wholly online units varied from Sex, Crime and Justice, Numeracy across the Curriculum, to Computers and Society and Professional Ethics. There are a further two levels of online presence as defined by the University. A basic online presence is the lowest level of online capability and a minimum requirement for all units. A basic online presence means that students are provided with a unit outline, some basic resources and an initial starting point for administrative contact. An extended online presence is one where at least one major teaching activity, such as lectures, tutorials, assessment or workshops, occurs online, or is significantly supplemented by online technologies. All of the other 1500 undergraduate and 700 postgraduate units offered have varying degrees of 'online-ness' ranging from basic to extended.

Data was collected for this part of the study via focus group sessions which were held at three Deakin University campuses in August 2005 with teaching staff. Focus groups are a useful way to explore whether there is a common view. Barnett (2006; p.2) suggests that the goal in organising focus groups is to investigate consensus experience, or attitudes/beliefs related to a clearly defined topic'. The purposefully selected staff were all experienced developers and implementers of online units in a broad range of areas, with all faculties and campuses across the University represented. The findings of these focus groups were then combined and presented at a workshop of the Asia-Pacific WebCT User Conference in September 2005, 
involving Australian and other external faculty. The workshop attendees were invited to confirm or challenge the findings from the Deakin groups to see whether these findings were representative of others undertaking similar teaching.

\section{The Deakin University focus groups}

Invitations to attend the focus groups were sent out to 35 staff across the three campuses. The invitees were academics with considerable expertise in teaching online as well as staff involved with supporting online teaching and learning. The sessions were held after hours on campus and refreshments were served. The duration of each focus group session was just over an hour, excluding socialisation time which occurred both before and after the sessions. A plain language statement, outlining the objectives of the research, was provided to each participant.

The sessions were facilitated by a senior member of the Teaching and Learning Institute at Deakin University who had experience in running focus group sessions. Two of the three researchers attended each session and took extensive notes. Technology in the form of a classroom performance system (CPS) was used to gather demographic and quantitative data from the participants. CPS technology is known by many different names such as electronic voting systems (Simpson \& Oliver 2007), class electronic response systems (Freeman, Bell, Comerton-Forde, Pickering \& Blayney, 2007) or by the nickname 'clickers'. The use of the clickers enabled this data to be collected from the participants quickly, easily and allowed for anonymity. For some of the staff it was the first time they had used such devices and it was an initial point of discussion early in the sessions.

At each of the sessions the participants were split into two groups. Each of the groups answered different questions with one of the group members recording results on butcher's paper. After about 20 minutes of discussion on each question the two groups reconvened and presented their findings. The discussion was then opened up to all participants.

The focus group participants were asked to comment on their understanding of culture and cultural difference in the educational setting and to identify different cultural influences that affected how their students learned. They were also asked to comment about how they might teach effectively and facilitate learning in a culturally diverse online environment. 


\section{The workshop of external faculty}

The workshop 'Good Practice for Culturally Inclusive Online Teaching and Learning' was conducted as part of the 6th Annual WebCT Asia Pacific User Conference in Cairns in September 2005. The workshop was open to all those attending the conference and no prior registration was required. The conference program foreshadowed the intent of the workshop so attendees could make an informed choice regarding their attendance and then self select to attend. The duration of the workshop was one hour. One of the researchers facilitated the discussion; the second researcher recorded participants comments on easily viewable butcher's paper while the third researcher took additional notes, summarising the session.

Attendees were given the same clickers as used in the Deakin University focus groups and a plain language statement explaining the research. The clickers were again used to gather demographic and other data from the participants allowing anonymity and ease of collection for this type of data.

The session was conducted as follows: a short introduction to the research was given; demographics were collected via the clickers (resulting in some hilarity as some struggled with the technology); and attendees were then shown the factors identified by the Deakin University focus groups. These factors were then presented in alphabetical order and were listed in turn allowing attendees to respond via the clickers.

In the last part of the session (about 20 minutes) attendees were given the opportunity to add factors not previously identified and to make comment about the list 'Best Practices at Deakin University' that was compiled from the Deakin focus groups. The workshop attendees were also asked 'Is it necessary to consider culture in the online environment?' and 'Is it possible to be inclusive in an online environment?'

\section{Results and discussion}

\section{The Deakin University focus groups}

In total there were 29 focus group participants, approximately twice as many females as males. All of the three major teaching campuses of Deakin University were represented. At each session the participants were split into two groups. In total five males and ten females across the three campuses considered the questions:

Question 1 (a): What is your understanding of culture and cultural difference in the educational setting?

Question 2 (a): How might you go about teaching effectively for cultural difference and diversity online? 
Five males and nine females across the three campuses considered the questions:

Question 1 (b): What are the different cultural influences that affect the way your students go about learning?

Question 2 (b): How might we as teachers facilitate learning in a culturally diverse online environment? In an ideal world? In the real world?

The demographics of the focus groups and the questions they were asked are shown in Table 1.

Table 1: Deakin University focus groups

\begin{tabular}{|c|c|c|c|c|}
\hline Campus & Group & $\begin{array}{l}\text { Questions } \\
\text { considered }\end{array}$ & Male & Female \\
\hline \multirow[t]{2}{*}{ A } & 1 & $1 a+2 a$ & 3 & 3 \\
\hline & 2 & $1 b+2 b$ & 2 & 3 \\
\hline \multirow[t]{2}{*}{ B } & 1 & $1 a+2 a$ & 1 & 3 \\
\hline & 2 & $1 b+2 b$ & 1 & 3 \\
\hline \multirow[t]{2}{*}{ C } & 1 & $1 a+2 a$ & 1 & 4 \\
\hline & 2 & $1 b+2 b$ & 2 & 3 \\
\hline \multicolumn{3}{|r|}{ Total } & 10 & 19 \\
\hline
\end{tabular}

Table 2 shows responses to some of the questions posed to ascertain the background and level of experience of the focus group participants in teaching online.

Table 2: Background of Deakin University focus group participants

\begin{tabular}{|c|c|c|c|c|c|c|c|c|c|}
\hline \multirow{2}{*}{\multicolumn{2}{|c|}{ Campus }} & \multicolumn{2}{|c|}{$\begin{array}{c}\mathrm{A} \\
\mathrm{n}=11\end{array}$} & \multicolumn{2}{|c|}{$\begin{array}{c}B \\
n=8\end{array}$} & \multicolumn{2}{|c|}{$\begin{array}{c}C \\
n=10\end{array}$} & \multicolumn{2}{|c|}{$\begin{array}{c}\text { Combined } \\
\mathrm{n}=29\end{array}$} \\
\hline & & $\mathrm{n}$ & $\%$ & $\mathrm{n}$ & $\%$ & $\mathrm{n}$ & $\%$ & $\mathrm{n}$ & $\%$ \\
\hline \multicolumn{2}{|c|}{ Used clickers before } & 6 & 55 & 0 & 0 & 1 & 10 & 7 & 24 \\
\hline \multicolumn{2}{|c|}{ Australian ethnicity } & 6 & 55 & 6 & 75 & 6 & 60 & 18 & 62 \\
\hline \multirow[t]{5}{*}{ Teaching online } & $<1$ year & 0 & 0 & 1 & 12 & 2 & 20 & 3 & 10 \\
\hline & $1-2$ years & 1 & 9 & 0 & 0 & 1 & 10 & 2 & 7 \\
\hline & 3-4 years & 2 & 18 & 3 & 38 & 1 & 10 & 6 & 21 \\
\hline & $5-6$ years & 2 & 18 & 2 & 25 & 3 & 30 & 7 & 24 \\
\hline & $>6$ years & 6 & 55 & 2 & 25 & 3 & 30 & 11 & 38 \\
\hline \multirow{5}{*}{$\begin{array}{l}\text { Online } \\
\text { facilitation }\end{array}$} & None & 1 & 9 & 0 & 0 & 2 & 20 & 3 & 10 \\
\hline & A little & 2 & 18 & 2 & 25 & 1 & 10 & 5 & 17 \\
\hline & Some & 0 & 0 & 2 & 25 & 5 & 50 & 7 & 24 \\
\hline & Experienced & 6 & 55 & 1 & 12 & 3 & 30 & 10 & 34 \\
\hline & $\begin{array}{l}\text { Extensive } \\
\text { experience }\end{array}$ & 2 & 18 & 3 & 38 & 0 & 0 & 5 & 17 \\
\hline \multicolumn{2}{|c|}{ Taught international students } & 11 & 100 & 8 & 100 & 10 & 100 & 29 & 100 \\
\hline \multicolumn{2}{|c|}{ Taught multi-modal/campus } & 8 & 73 & 7 & 88 & 6 & 60 & 21 & 72 \\
\hline
\end{tabular}


Most of the participants described themselves as having an Australian background (62\%) with the remainder indicating that they were European, Canadian or English. Most (83\%) had been teaching online for at least three years. About half indicated that they were either fairly experienced or had had extensive experience in online facilitation, which was defined as conducting tutorials online with active participation in the online discussions. All had taught international students before. Many had taught units offered on more than one campus (multi-campus) or had taught students studying in different modes (off campus, on campus).

\section{Culture, cultural difference and cultural influences}

The focus group participants identified a number of areas where culture and cultural difference were evident. The results of both Questions 1a and $1 \mathrm{~b}$ have been combined as, during discussion, the participants determined that the questions were essentially the same. The responses to the questions included:

- Ethnicity

- Learning styles

- Age

- Educational background

- Social class

- Language (not just limited to international students)

- Gender

- Level of study

- Generational background

- Degree of life experience

- Learning styles

- Attitudes towards education

- Religion

- Knowledge about and familiarity with technology and technical processes

- Expectations and attitudes

- Capacity of understanding of non-explicit information (rules)

- Socio-economic status

The overall consensus was that cultural diversity was anything within a student cohort that distinguished the individual student from the class norm. For example, the lone male student in a class of all females; a student who does not have the prescribed technical background or knowledge; or a student from non-English speaking background, unfamiliar with the teaching culture.

It was recognised that there is much diversity within forms of civilisation and customs of people. For example, there is diversity in respect to age, 
gender, socio-economic status, living conditions, and even personality. All of these factors can impact on an individual's learning. Learning approaches can vary greatly depending on where and how students received their schooling, and the home environment in which they were reared. While each student has a cultural background which will have shaped their understandings and expectations, it must be acknowledged that students within a culture are different - they may be shaped by the culture, but they are still individuals.

Cultural influences manifested themselves in a number of ways but particularly in classroom behaviours. Several participants spoke about the fact that Australian students appeared to be more active, reactive and positive in class; while on the whole the international student cohort, particularly those from Asian backgrounds, appeared to be less confident about their ability to communicate and to interact with the teacher and the rest of the class in an online environment.

\section{Teaching effectively for culturally diverse students online}

There were a number of areas identified by the focus group participants. Some of these related to areas beyond the participant's control such as the provision of teaching resources, appropriate for different learning styles; University supported staff training and development to raise awareness of issues and best practice related to cultural diversity; the introduction of student self paced learning with the restriction of a 13 week semester being removed (an ideal probably not achievable in the real world).

From personal perspectives, the participants spoke about the necessity of knowing and understanding students and their backgrounds; the development of clear guidelines with roles and expectations of both students and teachers clearly identified; and above all humanising the environment so that a greater sense of community is achieved.

Specific issues which impact on teaching culturally diverse online students and which met with general consensus include the following:

- Students from all cultures have the right to be respected but they have the responsibility to respect us and our culture too.

- International students vary greatly in their expectations; there are those who come to Australian universities to specifically experience Australian learning and culture and there are those studying via affiliated organisations who are less prepared to experience the Australian 'way'. 
- Many students are unprepared to take sufficient responsibility for their own learning. There is a gap between students' expectations and staff and university expectations.

- There is resistance amongst students to online learning environments as they see them as a cost saving measure (which all participants agreed that they are not). Students feel they are 'short changed' because of the limited or non-existent face to face interactions.

- Many students may be enrolled full time but generally cannot, or do not, devote sufficient time to study. Their time is taken up with work, family and play. However the curriculum is still a full time curriculum.

- Students do not value knowledge for knowledge's sake. Students' thirst for knowledge has been replaced by a thirst for a qualification - is this the result of economic rationalisation?

Other issues and concerns that were raised and received support from the group were:

- Administration issues relating to large classes and virtual classes. It is difficult to get to ' $k$ now' individual students.

- Cultural background is often not obvious when students are not seen and there is no opportunity for casual conversation. Even gender can be hidden.

- Areas where cultural differences have arisen online include turn taking routines, the use of humour, accepted conventions of courtesy, the time of replies, and the necessity for some students to be invited to participate.

- Awareness of characters and symbols that may reflect different beliefs or values for different groups.

- Language which appears to stereotype students. Careful choice of words, images and situations that avoid using qualifiers reinforcing racial and ethnic stereotypes.

- Improving group work capability by exposing students to technical and learning requirements early and minimising forming and norming stages (moving them faster into performing when needed).

- Use of some explanation to accommodate multiculturalism for the very culturally specific questions (e.g. local sport.)

- Extra time that it takes to teach well in the virtual classroom.

- Lack of control over the curriculum. Particular learning resources should be included in the curriculum as they are essential and beneficial for student learning and for future employment prospects even though they may be unpopular with students. Students often steer away from subjects which they consider 'hard' subjects (popularity polls versus good curriculum design).

Two specific suggestions proposed by the groups were: 
- Profiling students as an entry exercise. The profile lives with the student through their tenure at University and staff have access to it.

- Development of a common core University unit which will teach all students the generic skills, the realities of university life and learning, what is expected of them, technical skills, team work skills, exposure to multicultural issues, and give them an understanding of plagiarism, copyright, and so on.

In many institutions the second point is addressed in an ad hoc manner, through the provision of assorted transition and support programs to assist students into university life. Deakin University for example runs a First Year Initiative program during the first six weeks of the new academic year to assist students to assimilate into their new environment and provide them with an opportunity to obtain the skills to successfully negotiate their tenure at university. Student services also provide a variety of workshops during the academic year to help students with assignment preparation, communication skills, and the copyright and plagiarism maze for example. Unfortunately these programs are optional extras and it often seems that it is the well prepared students who make the effort to participate in these extra-curricula activities. The provision of a core unit encompassing these skills would ensure that all students were given the opportunity of gaining these necessary skills.

According to the participants, the facilitation of learning in a culturally diverse online environment could be achieved in an ideal world by customising the learning experience for each student. However this would require the provision of the same material in multiple learning modes, multiple feedback methods, and having expert leaders to facilitate the learning. One participant concluded:

In practice of course (so in the real world), compromises have to be made and all teachers can do is to have an attitude that values and respects cultural diversity and impart this to students.

\section{The workshop of external faculty}

In total 20 people attended the workshop. There were 16 clickers and these were issued to the first 16 participants who arrived. The demographics refer to those 16 attendees as the data was collected through the clickers. However the discussion during the workshop was collated from all of the 20 people who attended. Table 3 shows responses given by the group with respect to their backgrounds. Of the cohort of 16, there were 8 males and 8 females. Seven attendees $(44 \%)$ had used clickers before. Twelve people $(75 \%)$ had an Australian background. 
Table 3: Background of the workshop attendees

\begin{tabular}{|l|l|c|c|}
\hline \multirow{4}{*}{ Teaching online } & & No. & $\%$ \\
\cline { 2 - 4 } & $<1$ year & 1 & 6 \\
\cline { 2 - 4 } & $1-2$ years & 0 & 0 \\
\cline { 2 - 4 } & 3-4 years & 6 & 38 \\
\cline { 2 - 4 } & 5 -6 years & 5 & 31 \\
\cline { 2 - 4 } & $>6$ years & 4 & 25 \\
\hline \multirow{4}{*}{$\begin{array}{l}\text { Online } \\
\text { facilitation }\end{array}$} & None & 3 & 6 \\
\cline { 2 - 4 } & A little & 3 & 19 \\
\cline { 2 - 4 } & Some & 6 & 38 \\
\cline { 2 - 4 } & Fairly experienced & 1 & 19 \\
\cline { 2 - 4 } & Extensive experience & 2 & 12 \\
\hline \multirow{2}{*}{$\begin{array}{l}\text { Taught students } \\
\text { from different } \\
\text { cultures }\end{array}$} & Don't teach & 13 & 81 \\
\cline { 2 - 4 } & No & 3 & \\
\cline { 2 - 4 } & Yes & &
\end{tabular}

In general the workshop attendees verified most of the findings of the Deakin University focus groups, as Table 4 shows. The factors of attitudes to educational learning, education and prior learning, ethnicity and language, learning styles and socio-economic background were particularly well supported. In each case over $60 \%$ of attendees gave a score of 4 or 5, indicating agreement. Age and life experiences received the same level of support (44\%); while for personality traits there appeared to be a split with slightly more positive support (50\% positive with $37 \%$ negative).

Table 4: Ratings of findings of DU focus groups by the workshop attendees $(n=20)$

\begin{tabular}{|l|c|c|c|c|c|}
\hline \multirow{2}{*}{ Factor } & 1 & 2 & 3 & 4 & 5 \\
\cline { 2 - 6 } & $\begin{array}{c}\text { Not sig- } \\
\text { nificant } \%\end{array}$ & \multicolumn{4}{|c|}{$\begin{array}{c}\text { Very sig- } \\
\text { nificant } \%\end{array}$} \\
\hline Age & 6 & 6 & 44 & 6 & 38 \\
\hline Attitudes to educational learning & 0 & 0 & 19 & 50 & 31 \\
\hline Education and prior learning & 0 & 6 & 12 & 62 & 19 \\
\hline Ethnicity and language & 0 & 12 & 19 & 25 & 44 \\
\hline Gender & 19 & 31 & 38 & 12 & 0 \\
\hline Learning styles & 0 & 12 & 19 & 38 & 31 \\
\hline Life experiences & 0 & 12 & 44 & 31 & 12 \\
\hline Personality trait & 12 & 25 & 12 & 50 & 0 \\
\hline Religion & 19 & 38 & 12 & 25 & 6 \\
\hline Socio-economic background & 6 & 6 & 19 & 50 & 19 \\
\hline
\end{tabular}

Two findings that were not supported by the workshop attendees were religion (only $32 \%$ with positive ratings of 4 or 5 compared with $57 \%$ negative with ratings of 1 or 2); and gender, which received only $12 \%$ support with 50\% indicating a negative response. The fact that gender was 
not considered a factor is particularly surprising as the literature suggests that there are key areas where similarities or differences between male and female students might be significant in online learning (Meyers, Bennett \& Lysaght, 2004 for example). However, in the online environment gender is masked through the anonymous technological interface. It is not unusual to make assumptions about the gender of a student, particularly those with unfamiliar names, in the online environment, and then have the assumption disproved when the student appears at the office door. The higher proportion of males in the external workshop also may have impacted on the discrepancy with results from the Deakin focus groups.

A finding that was not identified as a factor of cultural diversity by the Deakin University focus group was physical disability. The consensus of the workshop attendees was that any physical disability was a factor that would differentiate a student from the cohort, and thus would cause them to be considered culturally diverse.

Fifteen of the 16 attendees (94\%) agreed that it was necessary to consider culture in the online environment and $13(81 \%)$ agreed that it was possible to be inclusive in an online environment.

In general, most of the attendees indicated that they agreed with the practices proposed by the Deakin University focus group participants. There was strong agreement that students should not be exposed to wholly online learning while in their first year of study. Many of the attendees spoke about the need to firstly solve technical, access and design issues in online learning environments. They advocated the use of a simple interface with intuitive navigation; the use of consistent icons to denote particular features and functionality; and the use of simple language with no slang or jargon. They also agreed that materials should be presented in different forms to cater for the varying learning styles of the student cohort. They suggested that text materials, where possible, should be supported by graphics in the form of images or diagrams.

Attendees suggested that discussion forums were an area where the teacher could be proactive in ensuring equity for all participating students. If set up and moderated well, the discussion forum could be an inclusive environment that allowed students the opportunity to reflect and revise answers; observe other students in discussions; and support those who were culturally different. Another area identified by the attendees was group work. They suggested that group membership for online groups could be 'socially engineered'. However this implies that the teacher is knowledgeable about the students and their backgrounds. A question posed by one of the participants 'Are online learning environments 
becoming more asexual?' resulted in lively discussion with no tangible outcome.

\section{Best practices}

The following list of 'Best practices for teaching culturally diverse students in online environments' has been compiled from the data collected in the Deakin focus groups and confirmed by the workshop attendees:

- Provide information about how to access the online unit by personal email or letter, i.e. outside the online environment;

- Humanise and introduce yourself and explain the protocol of addressing and communicating with staff;

- Provide a statement of equity online;

- Explicitly express the ground rules for behavioural expectations at the beginning of an online course. For example, the rules for entering into conversations in progress as well as respecting silence and taking turns in discussion;

- Explicitly outline student and staff expectations and responsibilities such as the speed with which queries will be answered and what type of feedback can be expected for submitted work;

- Design for one learning community rather than multiple cultural cohorts but recognise the different cohorts and learning styles when designing the curriculum;

- Use examples from different cultural settings and/or appeal to different cultural groups;

- When appropriate, use anonymity or nicknames to help lower cultural assumptions;

- Mix student groups to foster diversity;

- Provide time for reflection and understanding;

- Do not provide wholly online units for first year students (or if not possible then provide orientation to lessen the impact of transition);

- Provide an 'online social club' for students to interact and make connections;

- Treat your online class the same as if they were face to face by adopting similar good practices for inclusive teaching that are used in face to face classes.

The list of best practices is a practical set of guidelines for those teaching online culturally diverse students. It supports some of the principles for culturally inclusive and flexible instructional design that are found in the literature (see for example Ziguras 1999; McLoughlin \& Oliver 2000; Ngeow \& Kong 2002; Goodfellow \& Hewling 2005; Hannon \& D’Netto 2007). 


\section{Conclusions}

Online learning environments enable greater numbers of students of diverse educational and cultural backgrounds as well as modes of study to come together within the one virtual classroom. Consequently the cultural diversity of students in a virtual classroom is likely to be greater than in a physical classroom. However, many of the clues that enable staff and students to be culturally sensitive in physical classrooms are missing in the online world.

The research described here is in a particular context (Deakin University) and involves teaching staff who are familiar with online teaching practices and students from that university. However the findings from the research have been benchmarked with other external faculty involved with online teaching at tertiary institutions in Australia and overseas. Most of the general findings of the Deakin University faculty have been confirmed. A list of best practices for staff engaged in online teaching has been developed.

Overall it has been suggested that students need better preparation for learning in an online environment. As well as being better prepared to interact with the technologies for communication and collaboration, they also need to develop an understanding of the diversity in communication styles and develop the sensitivity for other cultures, if they are to become more successful communicators in the global, virtual workplace of the future.

\section{References}

Barnett, J. (2006). Focus groups tips for beginners. TCALL Occasional Research Paper No.1. http: / / www-tcall.tamu.edu/orp/orp1.htm [viewed 2 Aug 2006, verified 2 Oct 2007].

Campbell, M., Goold, A. \& Goward, P. (2004). Using online technologies: Does culture matter? In G. Richards (Ed.), Proceedings of World Conference on ELearning in Corporate, Government, Healthcare, and Higher Education, Chesapeake, VA: AACE. pp.2300-2307.

Chang, V. \& Fisher, D. (2003). The validation and application of a new learning environment instrument for online learning in higher education. In M. S. Khine \& D. Fisher (Eds.), Technology-rich learning environments: A future perspective. Singapore: World Scientific Publishing Co.

Choi, C. J. \& Kelemen, M. (1995). Cultural competences: Managing co-operatively across cultures. Brookfield, VT: Dartmouth Publishing. 
Das, R. (2005). Internationalisation of the curriculum: Putting theory into practice in a physiotherapy program. Journal of University Teaching and Learning Practice, 2(1), 25-35. http://jutlp.uow.edu.au/2005_v02_i01/das003.html

Freeman, M., Bell, A., Comerton-Forde, C., Pickering, J. \& Blayney, P. (2007). Factors affecting educational innovation with in class electronic response systems. Australasian Journal of Educational Technology, 23(2), 149-170. http: / / www.ascilite.org.au/ajet/ajet23/freeman.html

Goodfellow, R. \& Hewling, A. (2005). Reconceptualising culture in virtual learning environments: From an 'essentialist' to a 'negotiated' perspective. E-Learning, 2(4), 355-367.

Hannon, J. \& D'Netto, B. (2007). Cultural diversity online: Student engagement with learning technologies. International Journal of Educational Management, 21(5), 418432.

Jolley, A. (1997). Exporting education to Asia. Melbourne: Victoria University Press.

Jones, L. (2005). Maintaining the curricular philosophies of a multicultural education course: From face-to-face to eLearning environments. AACE Journal, 73(1), 91-99.

Liddicoat, A. (2004). The conceptualisation of the cultural component of language teaching in Australian language-in-education policy. Journal of Multilingual and Multicultural Development, 25(4), 297-317.

MacKinnon, D. \& Manathunga, C. (2003). Going global with assessment: What to do when the dominant culture's literacy drives assessment. Higher Education Research and Development, 22(2), 131-144.

Maslen, G. \& Slattery, L. (1994). Why our universities are failing. Melbourne: Wilkinson Books.

McLoughlin, C. \& Oliver, R. (2000). Designing learning environments for cultural inclusivity: a case study of indigenous online learning, Australian Journal of Educational Technology, 16(1), 58-72. http: / / www.ascilite.org.au/ajet/ajet16/mcloughlin.html

Meek, V. L. \& Harman, G. (1993). The binary experiment for higher education: An Australian perspective. Department of Administrative, Higher and Adult Education Studies. University of New England.

Meyers, W., Bennett, S. \& Lysaght, P. (2004). Asynchronous communication: Strategies for equitable e-learning. In Beyond the comfort zone: Proceedings ASCILITE 2004. http:/ / www.ascilite.org.au/conferences/perth04/procs/meyers.html

Ngeow, K. \& Kong, K. (2002). Designing culturally sensitive learning environments. In Winds of change in the sea of learning: Proceedings ASCILITE 2002, Auckland. http:/ / www.ascilite.org.au/ conferences/ auckland02/ proceedings/ papers/055.pdf

Oxford Reference Online Premium (2007). [viewed 11 Jan 2007] http: / / www.oxfordreference.com/ 
Sherry, C., Bhat, R., Beaver, B. \& Ling, A. (2004). Students as customers: The expectations and perceptions of local and international students. In Transforming knowledge into wisdom: Proceedings HERDSA 2004, Miri, Sarawak, 3-7 July. http:/ / www.herdsa.org.au/ conference2004/Contributions/RPapers/P017-jt.pdf

Simpson, V. \& Oliver, M. (2007). Electronic voting systems for lectures then and now: A comparison of research and practice, Australasian Journal of Educational Technology, 23(2), 187-208. http:/ / www.ascilite.org.au/ajet/ajet23/simpson.html

Singh, G., O'Donoghue, J. \& Worton, H. (2005). A study into the effects of eLearning on higher education. Journal of University Teaching and Learning Practice, 2(1), 1324. http:/ / jutlp.uow.edu.au/2005_v02_i01/pdf/odonoghue_003.pdf

Tylor, E. B. (1871). Primitive culture. London: John Murray.

Williams, R. (1983). Keywords, New York: Oxford UP.

Williams, T., Long, M., Carpenter, P. \& Hayden, M. (1993). Year 12 in the 1980's. Australian Council for Educational Research, Department of Employment, Education and Training. Canberra: Australian Government Publishing Service.

Ziguras, C. (1999). Cultural diversity and transnational flexible delivery. In Responding to diversity: Proceedings ASCILITE 1999. Brisbane, 5-8 December. http:/ / www.ascilite.org.au/ conferences/brisbane99/ papers / ziguras.pdf

Annegret Goold, School of Engineering and Information Technology, Deakin University, 221 Burwood Highway, Burwood, Victoria 3125, Australia. Email: agoold@deakin.edu.au

Annemieke Craig, School of Information Systems, Deakin University, Pigdons Road, Geelong, Victoria 3217, Australia. Email: acraig@deakin.edu.au

Dr Jo Coldwell, School of Engineering and Information Technology, Deakin University, Pigdons Road, Geelong, Victoria 3217, Australia. Email: jojo@deakin.edu.au 